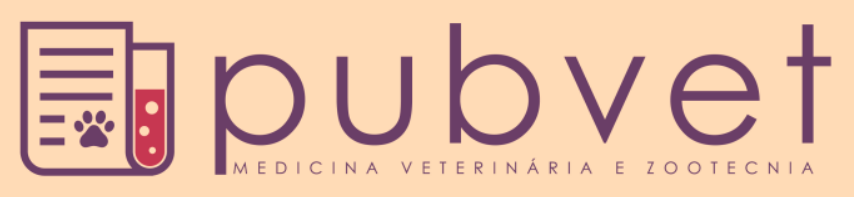

https://doi.org/10.31533/pubvet.v12n8a147.1-8

\title{
Espécies da família Euphorbiaceae na alimentação animal
}

\author{
George do Nascimento Araújo Júnior ${ }^{1^{*}}$, Marcondes de Sá Souza ${ }^{1} \bullet$, Vicente José \\ Laamon Pinto Simões ${ }^{1} \bullet$, Fabiana Torres Gomes ${ }^{2} \bullet$, Alexandre Maniçoba da Rosa \\ Ferraz Jardim $^{1}$, Maurício Luiz de Mello Vieira Leite $^{3 \bullet}$, Vicente Imbroisi Teixeira ${ }^{30}$, \\ Thieres George Freire da Silva ${ }^{30}$
}

${ }^{1}$ Mestrando em Produção Vegetal, Universidade Federal Rural de Pernambuco, Unidade Acadêmica de Serra Talhada - PE Brasil. ${ }^{2}$ Mestranda em Engenharia Agrícola, Universidade Federal do Vale do São Francisco - PE Brasil.

${ }^{3}$ Professor da Universidade Federal Rural de Pernambuco, Unidade Acadêmica de Serra Talhada-PE Brasil. E-mail: thigeoprofissional@ hotmail.com *Autor para correspondência: georgearaujo.agro@gmail.com

\begin{abstract}
RESUMO. A vegetação nativa da caatinga constitui um importante recurso alimentar para os rebanhos da região semiárida brasileira. Neste tipo de vegetação, a Família Euphorbiaceae é representada por um grande número de espécies, caracterizadas por um alto potencial produtivo e nutricional de sua forragem. No entanto, a falta de informações sobre o manejo acarreta problemas de desperdício de forragem na época das chuvas e intoxicação dos animais por substâncias presentes nas plantas, sendo necessário estudos que minimizem tais problemas. Desse modo, objetivou-se com esta revisão discorrer sobre a família botânica Euphorbiaceae, destacando a sua importância econômica e a utilização de algumas espécies nativas da caatinga na alimentação animal, mostrando as formas de utilização e caracterizando aspectos produtivos, químicos e nutricionais das forragens, assim como compostos tóxicos presentes nessas plantas.
\end{abstract}

Palavras chave: caatinga, forragem, intoxicação

\section{Species of the Euphorbiaceae family in animal Feed}

ABSTRACT. The native vegetation of the caatinga constitutes an important food resource for the herds of the Brazilian semiarid region. In this type of vegetation, the Euphorbiaceae Family is represented by a large number of species, characterized by a high productive and nutritional potential of their forage. However, the lack of managerial information causes problems of forage waste in the rainy season and animal intoxication by substances present in the plants, and studies are needed to minimize such problems. Thus, this review was aimed at discussing the botanical family Euphorbiaceae, highlighting its economic importance and the use of some native species of the caatinga in animal feed, showing the forms of use and characterizing the productive, chemical and nutritional aspects of forages as well as compounds toxins present in these plants.

Keywords: caatinga, forage, intoxication

\section{Especies de la familia Euphorbiaceae en alimentación animal}

RESUMEN. La vegetación nativa de la caatinga constituye un importante recurso de alimento para los rebaños de la región semiárida brasileña. En este tipo de vegetación, la Familia Euphorbiaceae está representada por un gran número de especies, caracterizadas por un alto potencial productivo y nutricional de su forraje. Sin embargo, la falta de información sobre el manejo acarrea problemas de desperdicio de forraje en la época de las lluvias e intoxicación de los animales por sustancias presentes en las plantas, siendo 
necesario estudios que minimicen tales problemas. De este modo, se objetivó con esta revisión discurrir sobre la familia botánica Euphorbiaceae, destacando su importancia económica y la utilización de algunas especies nativas de la caatinga en la alimentación animal, mostrando las formas de utilización y caracterizando aspectos productivos, químicos y nutricionales de los forrajes, así como compuestos tóxicos presentes en esas plantas.

Palabras clave: caatinga, forraje, intoxicación

\section{Introdução}

A criação de ruminantes é uma das atividades socioeconômicas mais importantes desenvolvidas pela população do semiárido brasileiro, onde as chuvas irregulares e a sazonalidade da produção de forragem ocasionam uma produção deficitária de alimentos para esses animais, sendo este, o maior desafio enfrentado pelos produtores nesta região para a criação dos rebanhos (Carvalho et al. 2017; Santos et al. 2017).

De acordo com Santos et al. (2011), a vegetação nativa constitui um importante recurso alimentar para os rebanhos da região semiárida brasileira. No entanto, na maioria dos casos essa alternativa se torna inviável por não atender as exigências nutricionais dos animais que, quando associada à escassez de forragem armazenada, resulta em baixa taxa de desempenho e rentabilidade na atividade agropecuária. Dessa forma, o uso de plantas forrageiras adaptadas às condições climáticas da região e que apresentem características nutricionais adequadas, juntamente com a prática de ensilagem (Moraes et al. 2013) e fenação (Arruda et al. 2010) aumentam o aporte forrageiro, principalmente nos períodos de estiagem (Carvalho et al. 2017). Nesse contexto, algumas espécies pertencentes à família Euphorbiaceae são consideradas importantes para a região, devido a sua abundância e características nutricionais (Carvalho et al. 2017). Estudos com favela (Cnidoscolus phyllacanthus (Muell. Arg.) Pax et K. Hoffman) (Pereira et al. 2012); maniçoba (Manihot glaziowii Mull.), mandioca (Manihot esculenta Crantz) e pornunça (híbrido natural de mandioca e maniçoba) (Ferreira et al. 2009; Santos et al. 2017) mostraram um alto potencial produtivo e nutricional na alimentação e performance animal.

Com base no exposto, objetivou-se com esta revisão discorrer sobre a família botânica Euphorbiaceae, destacando a sua importância econômica e a utilização de algumas espécies nativas da caatinga na alimentação animal, mostrando as formas de utilização e caracterizando aspectos produtivos, químicos e nutricionais das forragens, assim como compostos tóxicos presentes nessas plantas.

\section{Família Euphorbiaceae}

As espécies da família Euphorbiaceae estão distribuídas principalmente nas regiões tropicais do planeta, em especial nos continentes americano e africano, com poucos indivíduos inseridos nas regiões temperadas. Com um total de 8.000 espécies e distribuídas em 317 gêneros, a família divide-se ainda em 49 tribos e cinco subfamílias, conforme o sistema de classificação de (Webster (1994b); Sátiro \& Roque (2008); Lucena \& Alves (2010); Trindade \& Lameira (2015)). No Brasil, estima-se a ocorrência de 1.100 espécies e 72 gêneros, que podem ser encontradas nos mais diversos tipos de vegetação do país. A região Nordeste comporta cerca de 211 espécies e 45 gêneros, sendo 17 espécies endêmicas da Caatinga (Sátiro \& Roque 2008; Lucena \& Alves 2010). A Euphorbiaceae está entre as seis maiores e mais importantes famílias do grupo das Angiospermas (Secco et al. 2012) inclui plantas geralmente latescentes, monóicas ou dióicas, com flores diclinas, sendo pistiladas e caracterizadas pelo gineceu sincárpico, ovário súpero e geralmente tricarpelar. $\mathrm{O}$ fruto é geralmente capsular com deiscência explosiva, abrindo-se em três mericarpos, sendo conhecido como cápsula tricoca (Sátiro \& Roque 2008; Lucena \& Alves 2010). De modo geral, os representantes da família apresentam um rico potencial econômico, seja ele no âmbito medicinal (Cansanção) (Cnidoscolus vitifolius (Mill.) Pohl), (Lucena \& Alves 2010), industrial (Seringueira (Hevea brasiliensis), (Trindade \& Lameira 2015), madeireiro (Sangra d'água (Croton matourensis Aubl.), (Lucena \& Alves 2010), nutricional (Mandioca (Manihot esculenta Crantz), (Ferreira et al. 2009) e ornamental (Bico-de-Papagaio) (Euphorbia pulcherrima Willd. ex Klotzsch) (Trindade \& Lameira 2015). Devido ao grande número de espécies e a grande diversidade fenotípica das mesmas, a família apresenta muitos problemas taxonômicos, que alguns estudiosos ainda buscam elucidar. Inicialmente, Webster 
(1975) propôs uma classificação para a Euphorbiaceae, subdividindo-a em cinco subfamílias, que foram separadas em dois grupos, de acordo com o número de óvulos por lóculo: Phyllanthoideae e Oldfieldioideae, ambos com dois óvulos e Acalyphoideae, Crotonoideae e Euphorbioideae, com um óvulo. Em uma classificação revisada e estendida, Webster (1994a) propôs que Euphorbiaceae s.l. abrange cinco subfamílias: Phyllanthoideae, Oldfieldioideae, Crotonoideae, Acalyphoideae e Euphorbioideae, pertencentes a um único grupo. No entanto, de acordo com o sistema de classificação proposto pela Angiosperm Phylogeny Grupo, não há evidências que permitam a manutenção de Euphorbiaceae s.l. como um único grupo. Desse modo, a família foi então dividida em quatro: Euphorbiaceae sensu stricto, compreendendo àquelas subfamílias que apresentam apenas um óvulo por lóculo (Euphorbioideae, Crotonoideae e Acalyphoideae); Phyllanthaceae, incluindo as Phyllanthoideae (dois óvulos por lóculo no ovário - biovular); Picrodendraceae, incluindo as Oldfieldioideae (biovular) e Putranjivaceae (biovular, que compreende Drypetes Vahl. e Putranjiva Wall.) (Secco et al. 2012).

Quando se considera a grande variação taxonômica das espécies e a vasta expansão do território brasileiro é possível considerar que os estudos até hoje desenvolvidos deixam uma considerável lacuna sobre essa família, principalmente no Nordeste do Brasil, uma vez que é apontada por (Lucena \& Alves 2010), como uma das principais famílias que formam a vegetação dessa região.

\section{Uso de Euforbiáceas nativas da caatinga na alimentação animal}

Visto as potencialidades de algumas espécies da família Euphobiaceae para a alimentação animal no semiárido brasileiro, nesta seção serão discutidos alguns resultados obtidos de estudos com plantas do gênero Cnidoscolus e Manihot, destacando os aspectos produtivos e nutricionais, assim como, o desempenho dos animais submetidos à dieta com forragem de favela (Cnidoscolus phyllacanthus (Muell. Arg.) Pax et K. Hoffman), maniçoba (Manihot glaziowii Mull.) e pornunça (híbrido natural de mandioca e maniçoba).

\section{Favela [Cnidoscolus phyllacanthus (Muell. Arg.) Pax et K. Hoffman]}

$\mathrm{O}$ grande potencial forrageiro da favela ou faveleira (denominação que muda conforme a região) está nas folhas maduras fenadas e cascas novas, que são utilizadas na alimentação de rebanhos de caprinos, ovinos, muares e bovinos do Nordeste brasileiro (Pereira et al. 2012). Esses autores salientam o alto teor de matéria seca (93\%) e de matéria orgânica ( $89 \%$ ) encontrado no feno de favela, que se mostrou ser bem semelhante ao de outras espécies da caatinga, como a sabiá e florde-seda (Silva et al. 2010), catingueira (Gonzaga Neto et al. 2001) e mororó (Santos et al. 2010). De acordo com (Drumond et al. 2007), a concentração da matéria seca (MS) pode variar conforme os componentes da parte aérea dessas plantas, como pode ser visto na Tabela 1. Observa-se uma produção média de MS na parte aérea de $5,07 \mathrm{~kg}$, distribuídos nos fustes mais galhos grossos, com uma maior concentração da matéria seca produzida, cerca de $68,64 \%$, o que corresponde a $3,48 \mathrm{~kg}$, seguido dos galhos finos $(17,7 \%)$ e folhas $(13,6 \%)$.

Em trabalho realizado no município de Sertânia (PE) Pereira et al. (2012) encontraram no feno de favela teores de proteína bruta igual a $13,5 \%$, o que foi considerado baixo quando comparado com os valores obtidos por ( $\underline{\text { Santos et }}$ al. 2006) que obtiveram teor próximo de $25 \%$. Esse baixo teor pode estar relacionando ao estádio de maturidade no qual a planta foi colhida, uma vez que com o avanço da idade, diminui o teor de nitrogênio na planta, refletindo assim, em um menor teor proteico.

Tabela 1. Matéria verde (MV) e matéria seca (MS) de plantas de "faveleira" de vegetação secundária com aproximadamente três anos de idade, em Petrolina, Pernambuco

\begin{tabular}{lcccc}
\hline \multirow{2}{*}{ Componentes da planta } & \multicolumn{2}{c}{ Peso, kg } & \multicolumn{2}{c}{ Concentração, \% } \\
\cline { 2 - 5 } & MV & MS & MV & MS \\
\hline Folhas & $2,72 \pm 1,56$ & $0,69 \pm 0,41$ & 24,79 & 13,61 \\
Galhos finos & $2,04 \pm 1,38$ & $0,90 \pm 0,61$ & 18,60 & 17,75 \\
Fustes + galhos grosso & $6,21 \pm 3,30$ & $3,48 \pm 1,8$ & 56,61 & 68,64 \\
\hline Total & 10,97 & 5,07 & 100 & 100 \\
\hline
\end{tabular}

Fonte: Drumond et al. (2007). 
De acordo com Nascimento et al. (2006), plantas forrageiras com teor proteico inferior a $7 \%$, pode prejudicar a fermentação ruminal, problema esse que não será ocasionado com o feno de favela. No entanto, Pereira et al. (2012) e Drumond et al. (2007) relatam a importância de se obter o conhecimento sobre a qualificação dessa proteína através de estudos de fracionamento que permitam esclarecer a sua real disponibilidade.

Em relação aos demais componentes bromatológicos (Tabela 2), o feno de favela está dentro dos limites aceitáveis e com valores superiores a de outras forrageiras nativas.

Também foi observado comportamento semelhante em relação a outras espécies nativas, quando observado os valores de fibra em detergente neutro (FDN) $(41,9 \%)$ e fibra em detergente ácido (FDA) $(26,1 \%)$. De acordo com Cruz et al. (2010), os valores de FDN são considerados adequados, uma vez que um alimento com teor de FDN acima de $60 \%$, pode acarretar uma menor ingestão de matéria seca pelo animal, ocasionado pela limitação física do rúmen e, consequentemente, reduzindo a taxa de passagem do alimento pelo trato digestivo. Ainda na Tabela 2, os valores de carboidratos não fibrosos (CNF) $(30,36 \%)$, estão dentro da faixa adequada para a dieta de animais de alto potencial produtivo. Dessa forma, os teores de FDN e CNF encontrados no feno de favela, são indicativos de que o alimento apresenta boas características químicas do ponto de vista forrageiro (Pereira et al. 2012).
O consumo de alimento pelo animal é considerado um fator essencial para a avaliação do valor nutritivo da forragem, tendo em vista que o volume de nutrientes ingeridos e o desempenho dos animais, acontecem em função da quantidade e qualidade da forragem consumida. Neste contexto, diante da necessidade de consumo de matéria seca de $51,0 \mathrm{~g} \mathrm{~kg}^{-0,75}$ dia-1 para atender as exigências de ovinos com peso vivo médio de 25 $\mathrm{kg}$, observa-se na Tabela 3 que o feno de favela atende à demanda destes animais. Levando em consideração a necessidade proteica de $2,9 \mathrm{~g} \mathrm{~kg}^{1}$ de $\mathrm{PV}^{0,75}$, percebe-se na Tabela 3 , que esse valor se encontra abaixo do qual o feno de favela pode fornecer, indicando seu grande potencial para atender à necessidade diária de PB destes animais, possibilitando ainda, incremento na produção de carne e leite (Pereira et al. 2012).

Quando observados os valores médios dos coeficientes de digestibilidade "in vivo" dos componentes bromatológicos do feno de favela (Tabela 4), percebe-se que os mesmos, com exceção do extrato etério (EE), apresentaram-se acima de 50\% para as frações estudadas por Pereira et al. (2012). De acordo com Matos et al. (2005), altos coeficientes de digestibilidade e conteúdo de $\mathrm{PB}$, assim como o consumo e a digestibilidade da MS, são os critérios mais utilizados para demonstrar o valor nutritivo de uma espécie forrageira. Os valores de digestibilidadein vivo da MS do feno de favela, encontrados por Drumond et al. (2007) e Pereira et al. (2012), de 63,7\% e $65,5 \%$, respectivamente, se mostram superior ao de outras espécies da caatinga estudadas por Gonzaga Neto et al. (2001).

Tabela 2. Teores de matéria seca (MS), matéria orgânica $(\mathrm{MO})$, proteína bruta ( $\mathrm{PB}$ ), extrato etéreo (EE), extrato não nitrogenado (ENN), fibra em detergente neutro (FDN), fibra em detergente ácido (FDA), carboidratos não fibrosos (CNF), fósforo (P) e cálcio (Ca) em feno de faveleira (Cnidoscolus hyllacanthus (Muell. Arg.) Pax et K. Hoffman), em Sertânia, PE

\begin{tabular}{cccccccccc}
\hline \multicolumn{10}{c}{ Composição, \% MS } \\
\hline MS & MO & PB & EE & ENN & FDN & FDA & CNF & P & Ca \\
\hline 92,95 & 89,28 & 13,48 & 3,52 & 41,42 & 41,92 & 26,71 & 30,36 & 0,08 & 4,42 \\
$\pm 0,56$ & $\pm 2,41$ & $\pm 1,48$ & $\pm 0,35$ & $\pm 3,72$ & $\pm 2,51$ & $\pm 1,60$ & $\pm 2,42$ & $\pm 0,01$ & $\pm 0,35$ \\
\hline
\end{tabular}

Fonte: Pereira et al. (2012).

Tabela 3. Consumo médio diário de matéria seca (MS), proteína bruta (PB), nutrientes digestíveis totais (NDT), fibra em detergente neutro (FDN) e fibra em detergente ácido (FDA) do feno de faveleira (Cnidoscolus phyllacanthus (Muell. Arg.) Pax et K. Hoffman), Sertânia (PE)

\begin{tabular}{lcccccc}
\hline \multirow{2}{*}{ Feno } & \multicolumn{5}{c}{ Consumo em g kg-1 $\mathrm{de} \mathrm{PV}^{0,75}$} \\
\cline { 2 - 7 } & $* \mathrm{MS}$ & $* \mathrm{~PB}$ & $* \mathrm{NDT}$ & $* \mathrm{FDN}$ & $* \mathrm{FDA}$ & $* \mathrm{CNF}$ \\
\hline Média & 93,14 & 12,52 & 56,06 & 39,04 & 24,88 & 28,28 \\
DP & $\pm 4,12$ & $\pm 0,56$ & $\pm 2,30$ & $\pm 2,74$ & $\pm 1,24$ & $\pm 1,25$ \\
\hline
\end{tabular}

Média e desvio padrão de cinco repetições. *valores calculados com base na matéria seca. Fonte: Pereira et al. (2012). 
Tabela 4. Teores de digestibilidade da matéria seca (MS), matéria orgânica (MO), proteína bruta (PB), extrato etéreo (EE), extrato não nitrogenado (ENN), fibra em detergente neutro (FDN) e fibra em detergente ácido (FDA) do feno de faveleira (Cnidoscolus phyllacanthus (Muell. Arg.) Pax et K. Hoffman), Sertânia, PE

\begin{tabular}{lcccccccc}
\hline Feno & \multicolumn{7}{c}{ Coeficientes de digestibilidade, \% MS } \\
\hline Média & MS & MO & PB & EE & ENN & FDN & FDA & CNF \\
DP & 63,66 & 66,06 & 74,52 & 36,44 & 74,32 & 57,32 & 54,77 & 56,91 \\
& $\pm 3,51$ & $\pm 3,08$ & $\pm 2,32$ & $\pm 8,56$ & $\pm 2,58$ & $\pm 2,93$ & $\pm 2,80$ & $\pm 4,80$ \\
\hline
\end{tabular}

Média e desvio padrão de cinco repetições. Fonte: Pereira et al. (2012).

De acordo com Drumond et al. (2007), os valores elevados de consumo e digestibilidade da $\mathrm{PB}$ e MS no feno de favela são sugestivos ao desenvolvimento de novas pesquisas que visem o desenvolvimento de práticas de manejo cultural, colheita e produção de forragem conservada (feno ou silagem) e desempenho animal, assim, a sua utilização poderá ser otimizada e consolidada como uma alternativa viável para suplementação alimentar dos rebanhos presentes na região semiárida.

\section{Maniçoba (Manihot glaziowii Mull.), mandioca (Manihot esculenta Crantz) e pornunça (híbrido natural de mandioca e maniçoba)}

As espécies do gênero Manihot apresentam alta resistência à seca e tolerância a solos pobres e ácidos, além de alto valor nutricional e elevado potencial produtivo, destacando-se a mandioca, maniçoba e o híbrido natural entre a maniçoba e a mandioca, conhecido como pornunça (Ferreira et al. 2009). De acordo com Dantas et al. (2008), a qualidade dessas forrageiras evidencia-se pelo alto teor de proteína e elevado teor de carboidratos não solúveis quando comparada com outras forrageiras tropicais, como a gliricidia (Gliricidia sepium (Jacq) e o capim Buffel (Cenchrus ciliaris L.) (Carvalho et al. 2017).

A parte aérea das euforbiáceas é considerada uma alternativa para aumentar a viabilidade econômica e a produtividade da pecuária da região Nordeste, visto que possuem alto valor nutritivo e boa aceitabilidade pelos animais. Ferreira et al.
(2009) ao avaliarem a produção de matéria seca (MS) e matéria verde (MV) da parte aérea da mandioca, maniçoba e pornunça, verificaram maiores valores para o híbrido, que apesentou produtividade de MS e MV iguais a 468,31 e $1629,47 \mathrm{~kg} \mathrm{ha}^{-1}$, respectivamente, seguida da mandioca $\left(178,12 \mathrm{~kg} \mathrm{ha}^{-1}\right.$ de MS e 833,25 kg ha-1 de MV) e maniçoba (99,35 $\mathrm{kg} \mathrm{ha}^{-1}$ de MS e $287 \mathrm{~kg}$ $\mathrm{ha}^{-1}$ de MV). Visando a viabilidade econômica na produção de caprinos no estado de Pernambuco, Lima Júnior et al. (2015) avaliaram o ganho de peso e rendimento da carcaça de caprinos da raça Moxotó alimentados com feno de Tifton 85 e feno de maniçoba e puderam observar que não houve diferença entre as variáveis analisadas (Tabela 7), mostrando que o feno de Tifton 85 pode ser substituído pelo o feno de maniçoba, o que pode trazer benefícios para o produtor, dentre eles a diminuição nos custos de produção.

Em trabalho realizado por Carvalho et al. (2017) no município de Petrolina (PE) cordeiros alimentados com silagem de pornunça ou gliricidia apresentaram maior peso corporal final (FBW), ganho de peso total (TWG) e ganho de peso diário (ADG), quando comparados com àqueles alimentados com silagem de capim Buffel, o que mostra o grande potencial dessa euforbiácea na alimentação animal. Quando comparado os valores de ingestão dos componentes bromatológicos das silagens de capim capim Buffel e pornunça, a euforbiácea se sobressaiu quando observado a quantidade ingerida de matéria seca, matéria orgânica,

Tabela 5. Pesos e rendimentos de carcaça de caprinos Moxotó alimentados com feno de Tifton 85 ou feno de Maniçoba

\begin{tabular}{|c|c|c|c|}
\hline Variável & Tifton 85 & Maniçoba & $\mathrm{CV}(\%)$ \\
\hline Consumo de matéria seca, $\mathrm{g} \mathrm{dia}^{-1}$ & $415,92 \mathrm{a}$ & $544,22 \mathrm{a}$ & 51,33 \\
\hline Ganho em peso, $\mathrm{g} \mathrm{dia}^{-1}$ & $10,00 \mathrm{a}$ & $9,00 \mathrm{a}$ & 115,38 \\
\hline Peso inicial, $\mathrm{kg}$ & $22,08 \mathrm{a}$ & $21,53 \mathrm{a}$ & 18,10 \\
\hline Peso corporal ao abate, $\mathrm{kg}$ & $22,54 \mathrm{a}$ & $21,12 \mathrm{a}$ & 11,63 \\
\hline Peso da carcaça quente, $\mathrm{kg}$ & $10,22 \mathrm{a}$ & $9,45 \mathrm{a}$ & 14,35 \\
\hline Rendimento da carcaça quente, $\%$ & $45,33 \mathrm{a}$ & $44,64 \mathrm{a}$ & 4,58 \\
\hline Peso da carcaça fria, $\mathrm{kg}$ & $9,57 \mathrm{a}$ & $8,85 \mathrm{a}$ & 14,09 \\
\hline
\end{tabular}

Médias seguidas de letras diferentes, na mesma linha, diferem significativamente entre si, pelo teste de Tukey a $5 \%$ de probabilidade. $\mathrm{CV}=$ Coeficiente de variação. Fonte: Lima Júnior et al. (2015). 
proteína bruta, carboidratos não fibrosos e nutrientes digestíveis totais (Tabela 6).

De forma geral, os animais alimentados com silagens de pornunça apresentaram melhor desempenho nutricional e, consequentemente, melhor performance na produção em comparação com àqueles que foram alimentados com silagem de capim Buffel (Carvalho et al. 2017), podendo ser utilizado em sistemas de produção animal na região semiárida de Pernambuco.

Tabela 6. Ingestão de matéria seca (MS), matéria orgânica (MO), proteína bruta (PB), fibra em detergente neutron corrigida para cinza e proteína (FDNcp), carboidratos nãofibrosos (CNF), e nutrientes digestíveis totais (NDT) por ovinos alimentados com dietas contendo silagens de diferentes forrageiras tropicais

\begin{tabular}{lcccc}
\hline Ingestão, & \multicolumn{4}{c}{ Silagens usadas na dieta } \\
\cline { 2 - 5 } kg/dia & Erva-sal & Capim-Buffel & Gliricidia & Pornunça \\
\hline MS & $1.08 \mathrm{a}$ & $0.74 \mathrm{c}$ & $0.86 \mathrm{bc}$ & $0.99 \mathrm{ab}$ \\
$\mathrm{MO}$ & $0.97 \mathrm{a}$ & $0.66 \mathrm{c}$ & $0.79 \mathrm{bc}$ & $0.92 \mathrm{ab}$ \\
$\mathrm{PB}$ & $0.19 \mathrm{a}$ & $0.10 \mathrm{c}$ & $0.11 \mathrm{c}$ & $0.16 \mathrm{~b}$ \\
FDNcp & $0.26 \mathrm{ab}$ & $0.28 \mathrm{a}$ & $0.20 \mathrm{~b}$ & $0.23 \mathrm{~b}$ \\
CNF & $0.50 \mathrm{a}$ & $0.24 \mathrm{c}$ & $0.42 \mathrm{~b}$ & $0.49 \mathrm{a}$ \\
NDT & $0.74 \mathrm{a}$ & $0.46 \mathrm{~b}$ & $0.62 \mathrm{a}$ & $0.68 \mathrm{a}$ \\
\hline
\end{tabular}

Médias seguidas de mesma letra na linha não diferem pelo valor de $\mathrm{P}<0,05$. Fonte: Carvalho et al. (2017).

\section{Intoxicação por Euforbiáceas forrageiras}

Apesar de apresentarem elevado potencial nutricional para serem utilizadas na alimentação animal, as euforbiáceas forrageiras estão entre as famílias que possuem plantas que produzem substâncias tóxicas, como o tanino e o ácido cianídrico. Essas substâncias quando ingeridas em quantidades inadequadas, podem acarretar danos ao rebanho, que variam de uma leve intoxicação à morte do animal, nos casos mais severos. Em época de estiagem, quando há um déficit na oferta de alimentos na região semiárida, as chances de ocorrerem intoxicações aumentam, seja pela invasão do rebanho a uma propriedade produtora, seja pelo manejo inadequado da forragem pelo produtor.

Em trabalho realizado com maniçoba (Manihot pseudoglazovii), flor-de-seda (Calotropis procera), feijão-bravo (Capparis flexuosa, L) e jureminha (Desmanthus virgatus), Cruz et al. (2010) observaram baixa concentração de taninos condensados, principalmente nas folhas de maniçoba, que apresentaram concentração igual a $32,3 \%$. De maneira geral, o principal enfoque dado à presença de taninos nas plantas forrageiras é sua ação anti-nutricional quando em altas concentrações. No entanto, o seu consumo pelos ruminantes, em concentrações entre 3 e $4 \%$ da MS, pode ocasionar respostas positivas, como a proteção da proteína alimentar contra a excessiva degradação ruminal, menor desperdício da amônia, o aumento da absorção de aminoácidos e a prevenção ao timpanismo (Cruz et al. 2010). De acordo com Amorim et al. (2005), além dos taninos condensados, o ácido cianídrico $(\mathrm{HCN})$ é outra substância tóxica presente em plantas de Manihot spp. que pode trazer sérios problemas aos animais. De acordo com Escodro (2016), a intoxicação por plantas cianogênicas (aquelas que possuem $\mathrm{HCN}$ em sua composição química) é a que mais causa perdas econômicas significativas na produção animal. Na região Nordeste há numerosos históricos da ocorrência de intoxicação por esta substância em bovinos e caprinos alimentados com Manihot spp., o que não é observado para equinos, uma vez que não se utiliza essa matéria prima na alimentação desses animais e por conta da grande seletividade alimentar da espécie (Escodro 2016).

Em trabalho realizado por Amorim et al. (2005) avaliando a ocorrência de intoxicação em caprinos da raça Moxotó alimentados com maniçoba (Manihot gaziovii), foi observado sinais clínicos de intoxicação nestes animais quando ingeriram o alimento poucas horas depois de serem colhidos, com posterior recuperação dos mesmos. No entanto, aqueles animais que imediatamente ingeriram o alimento apresentaram sinais de intoxicação, chegando a morte no dia seguinte (Tabela 5). De acordo com Bosak et al. (2017), tanto a toxidez, quanto a velocidade de ingestão das plantas cianogênicas são considerados os fatores mais importantes para a ocorrência da intoxicação em animais, que geralmente ocorrem quando doses tóxicas são ingeridas em curto período de tempo. Amorim et al. (2005) afirmam que a dose tóxica de HCN é de 2 a $4 \mathrm{mg}$ de $\mathrm{HCN}$ por $\mathrm{kg}$ de peso vivo por hora.

É possível perceber ainda que quando os caprinos da raça Moxotó se alimentaram da forragem com 120 horas de colhidas e armazenados em sacos plásticos, estes não apresentaram sinais de intoxicação, resposta que se deve ao fato de que nesse alimento as concentrações de $\mathrm{HCN}$ poderiam ter diminuído. De acordo com Amorim et al. (2005), plantas cianogênicas perdem o $\mathrm{HCN}$ quando cortadas, dessecadas ou quando submetidas ao processo de volatilização, portanto o feno preparado a partir de uma plantação potencialmente perigosa será, quando bem seco, seguro para a alimentação de animais. 
Tabela 7. Experimento em caprinos com as folhas de Manihot glaziovii não trituradas e conservadas dentro de saco plástico, na dosagem de $12 \mathrm{~g} / \mathrm{kg}$

\begin{tabular}{|c|c|c|c|c|c|c|c|}
\hline $\begin{array}{l}\text { Caprino }{ }^{\circ} \\
\text { (Peso) }\end{array}$ & $\begin{array}{c}\text { Data do } \\
\text { experimento }\end{array}$ & $\begin{array}{c}\text { Período de } \\
\text { intoxicação após } \\
\text { a colheita }\end{array}$ & $\begin{array}{l}\text { Dose } \\
\mathrm{g} / \mathrm{kg}\end{array}$ & $\begin{array}{l}\text { Início/ fim da } \\
\text { administração } \\
\text { (Horário) }\end{array}$ & $\begin{array}{c}\text { Início dos } \\
\text { sintomas } \\
\text { (Horário) }\end{array}$ & $\begin{array}{l}\text { Administração do } \\
\text { tiossulfato de } \\
\text { sódio (Horário) }\end{array}$ & $\begin{array}{c}\text { Recuperação } \\
\text { (Horário) }\end{array}$ \\
\hline $51(9,7 \mathrm{~kg})$ & 23.01 .04 & 4 horas & 7,4 & $15: 00 / 16: 27$ & $3: 55$ & $16: 30$ & $16: 36$ \\
\hline $59(11 \mathrm{~kg})$ & 23.01 .04 & 4horas & 12 & $15: 00 / 15: 30$ & $15: 30$ & $15: 40$ & $15: 45$ \\
\hline $38(11 \mathrm{~kg})$ & 23.01 .04 & 8 horas & 12 & $17: 12 / 18: 15$ & $18: 15$ & $18: 34$ & $18: 37$ \\
\hline $56(11 \mathrm{~kg})$ & 23.01 .04 & 8 horas & 12 & $17: 12 / 17: 40$ & $17: 50$ & 18:02 & Morto \\
\hline $\mathrm{s} / \mathrm{n}(9,2 \mathrm{~kg})$ & 27.01 .04 & 12 horas & 6,6 & $18: 15$ / 19:10 & $19: 00$ & $19: 25$ & $19: 32$ \\
\hline $39(11,4 \mathrm{~kg})$ & 27.01 .04 & 12 horas & 12 & 18:05 / 19:35 & $19: 50$ & $20: 48$ & $21: 00$ \\
\hline $37(11,5 \mathrm{~kg})$ & 30.01 .04 & 16 horas & 12 & 8:05 / 8:50 & 9:00 & $9: 45$ & $9: 53$ \\
\hline $43(8,9 \mathrm{~kg})$ & 30.01 .04 & 16 horas & 7,1 & $8: 05$ / 8:45 & $8: 45$ & $10: 30$ & $10: 30$ \\
\hline $32(14,4 \mathrm{~kg})$ & 30.01 .04 & 20 horas & 12 & $10: 57 / 11: 15$ & $11: 50$ & $12: 05$ & $12: 12$ \\
\hline $97(13,8 \mathrm{~kg})$ & 30.01 .04 & 20 horas & 12 & $10: 57 / 11: 43$ & $12: 00$ & $12: 40$ & $12: 43$ \\
\hline $54(10,8 \mathrm{~kg})$ & 24.01 .04 & 24 horas & 9 & 9:30 / 10:40 & $10: 40$ & $10: 55$ & 11:00 \\
\hline $58(12,2 \mathrm{~kg})$ & 24.01 .04 & 24 horas & 12 & 9:30 / 10:00 & $9: 55$ & $10: 30$ & $10: 35$ \\
\hline $51(11,2 \mathrm{~kg})$ & 11.03 .04 & 48 horas & 12 & $8: 50 / 9: 30$ & $10: 00$ & $10: 25$ & $10: 33$ \\
\hline $58(13,7 \mathrm{~kg})$ & 11.03 .04 & 48 horas & 12 & $8: 50 / 9: 15$ & $10: 20$ & $10: 38$ & $10: 45$ \\
\hline $54(12,7 \mathrm{~kg})$ & 12.03 .04 & 72 horas & 7,9 & $8: 15 / 9: 20$ & $9: 20$ & $9: 40$ & $9: 45$ \\
\hline $40(13,9 \mathrm{~kg})$ & 03.04 .04 & 96 horas & 6 & 9:11 / 10:00 & 10:00 & $10: 15$ & $10: 20$ \\
\hline $\mathrm{s} / \mathrm{n}(9,5 \mathrm{~kg})$ & 04.04 .04 & 120 horas & 12 & 9:20/11:15 & $\mathrm{ss}^{\mathrm{a}}$ & $13: 05$ & $\mathrm{ss}^{\mathrm{a}}$ \\
\hline $01(9,0 \mathrm{~kg})$ & 04.04 .04 & 120 horas & 12 & 9:20 / 11:00 & $\mathrm{ss}^{\mathrm{a}}$ & $13: 05$ & $\mathrm{ss}^{\mathrm{a}}$ \\
\hline
\end{tabular}

$\mathrm{ss}^{\mathrm{a}}=$ Sem sinais clínicos. Fonte: Amorim et al. (2005).

\section{Considerações finais}

Visto a importância de algumas espécies dessa família como alimento para os rebanhos do Semiárido brasileiro, são necessários mais estudos que visem o melhor aproveitamento da forragem, garantindo uma segurança alimentar, $\mathrm{e}$ as melhores formas de utilização, uma vez que o uso indevido pode acarretar problemas de intoxicação crônica e, em alguns casos, intoxicação aguda nos animais.

\section{Referências Bibliográficas}

Amorim S.L., Medeiros R.M.T. \& Riet-Correa F. 2005. Intoxicação experimental por Manihot glaziovii (Euphorbiaceae) em caprinos. Pesquisa Veterinária Brasileira 25, 179-87.

Arruda A.M.V., Fernandes R.T.V., Oliveira J.F., Filgueira T.M.B., Fernandes D.R. \& Galvão R.J.D. 2010. Valor energético de fenos de forrageiras do semi-árido para aves Isa Label. Acta Veterinaria Brasilica 4, 105-12.

Bosak P.A., Lustosa S.B.C. \& Sandrini J.M.F. 2017. Intoxicação de bovinos por ácido cianogênico e nitrito/nitrato em pastagens de manejo intensivo. PUBVET 11, 947-1073.

Carvalho G.G.P., Rebouças R.A., Campos F.S., Santos E.M., Araújo G.G.L., Gois G.C.,
Oliveira J.S., Oliveira R.L., Rufino L.M.A. \& Azevedo J.A.G. 2017. Intake, digestibility, performance, and feeding behavior of lambs fed diets containing silages of different tropical forage species. Animal Feed Science and Technology 228, 140-8.

Cruz B.C.C., Santos-Cruz C.L., Pires A.J.V., Rocha J.B., Santos S. \& Bastos M.P.V. 2010. Composição bromatológica da silagem de capim-elefante com diferentes proporções de casca desidratada de maracujá (Passiflora edulis Sims f. flavicarpa). Revista Brasileira de Ciências Agrárias 5, 434-40.

Dantas F.R., Araújo G.G.L., Silva D.S., Pereira L.G.R., Gonzaga Neto S. \& Tosto M.S.L. 2008. Composição química e características fermentativas de silagens de maniçoba ("Manihot" sp.) com percentuais de co-produto de vitivinícolas desidratado. Revista Brasileira de Saúde e Produção Animal 9, 247-57.

Drumond M.A., Salviano L., Cavalcanti N.B. \& Pereira L.G.R. 2007. Produção, distribuição da biomassa e composição bromatológica da parte aérea da faveleira. Revista Brasileira de Ciências Agrárias 2, 308-10.

Escodro P.B. 2016. Intoxicação natural por Manihot esculenta em equinos-Relato de 
casos. Brazilian Journal of Veterinary Medicine 38, 382-6.

Ferreira A.L., Silva A.F., Pereira L.G.R., Braga L.G.T., Moraes S.A.d. \& Araújo G.G.L. 2009. Produção e valor nutritivo da parte aérea da mandioca, maniçoba e pornunça. Revista Brasileira de Saúde e Produção Animal 10, 129-36.

Gonzaga Neto S., Batista Â.M.V., Carvalho F.F.R., Martínez R.L.V., Barbosa J.E.A.S. \& Silva E.O. 2001. Composição bromatológica, consumo e digestibilidade in vivo de dietas com diferentes níveis de feno de catingueira (Caesalpinea bracteosa), fornecidas para ovinos Morada Nova. Revista Brasileira de Zootecnia 30, 553-62.

Lima Júnior D.M., Carvalho F.F.R., Ferreira B.F., Batista Â.M.V., Ribeiro M.N. \& Monteiro P.d.B.S. 2015. Maniçoba hay feeding Moxotó goats. Semina: Ciências Agrárias 36, 2211-22.

Lucena M.F.A. \& Alves M. 2010. Notas taxonômicas para Euphorbiaceae sl do Nordeste do Brasil. Hoehnea 37, 71-85.

Matos D.S., Guim A., Batista Â., Pereira O.G. \& Martins V. 2005. Composição química e valor nutritivo da silagem de maniçoba (Manihot epruinosa). Archivos de zootecnia 54, 619-29.

Moraes S.D., Jobim C.C., Silva M.S. \& Marquardt F.I. 2013. Produção e composição química de híbridos de sorgo e de milho para silagem. Revista Brasileira de Saúde e Produção Animal 14, 624-34.

Nascimento M., Nascimento H., Oliveira M. \& Ribeiro V.L. 2006. Análise do crescimento e do valor forrageiro de mata-pasto para a produção de feno. Revista Caatinga 19, 21520.

Pereira V.L.A., Alves F.A.L., Silva V.M. \& Oliveira J.C.V. 2012. Valor nutritivo e consumo voluntário do feno de faveleira fornecido a ovinos no semiárido pernambucano. Revista Caatinga 25, 96-101.

Santos J.C., Nunes L.D., Dantas J.P., Nóbrega S.B.P. \& Prasad S. 2006. Química e Bromatológica da forragem da faveleira (Cnidoscolus quercifolius). Periódico Tchê Química, Porto Alegre 3, 31-42.

Santos K.C., Magalhães A.L.R., Silva D.K.A., Araújo G.G.L., Fagundes G.M., Ybarra N.G. \&
Abdalla A.L. 2017. Nutritional potential of forage species found in Brazilian Semiarid region. Livestock science 195, 118-24.

Santos M.V.F., Lira M.A., Dubeux Junior J.C.B., Guim A., Mello A.C.L. \& Cunha M.V.d. 2010. Potential of caatinga forage plants in ruminant feeding. Revista Brasileira de Zootecnia 39, 204-15.

Santos P.M., Voltolini T.V., Cavalcante A.C.R., Pezzopane J.R.M., Moura M.S.B., Silva T.G.F. \& Bettiol G.M. 2011. Mudanças climáticas globais e a pecuária: cenários futuros para o Semiárido brasileiro. Revista Brasileira de Geografia Física 4, 1176-96.

Sátiro L.N. \& Roque N. 2008. A família Euphorbiaceae nas caatingas arenosas do médio rio São Francisco, BA, Brasil. Acta Botânica Brasileira 22, 99-118.

Secco R.S., Cordeiro I., Senna-Vale L., Sales M.F., Lima L.R., Medeiros D., Haiad B.S., Oliveira A.S., Caruzo M.B.R. \& CarneiroTorres D. 2012. An overview of recent taxonomic studies on Euphorbiaceae sl in Brazil. Rodriguésia 63, 227-42.

Silva J.G.M., Costa Lima G.F., Aguiar E.M., Melo A.A.S. \& Rêgo M.M.T. 2010. Cactáceas nativas associadas a fenos de flor de seda e sabiá na alimentação de borregos. Revista Caatinga 23, 123-9.

Trindade M.T. \& Lameira O.A. 2015. Espécies úteis da família Euphorbiaceae no Brasil. Revista Cubana de Plantas Medicinales 19.

Webster G.L. 1975. Conspectus of a new classification of the Euphorbiaceae. Taxon Bronx 24, 593-601.

Webster G.L. 1994a. Classification of the Euphorbiaceae. Annals of the Missouri Botanical Garden 81, 3-32.

Webster G.L. 1994b. Synopsis of the genera and suprageneric taxa of Euphorbiaceae. Annals of the Missouri Botanical Garden 81, 33-144.

\footnotetext{
Recebido: 21 Mai. 2018.

Aprovado: 19 Jun.. 2018

Publicado: 30 Jul. 2018
}

Licenciamento: Este artigo é publicado na modalidade Acesso Aberto sob a licença Creative Commons Atribuição 4.0 (CC-BY 4.0), a qual permite uso irrestrito, distribuição, reprodução em qualquer meio, desde que o autor e a fonte sejam devidamente creditados 